\title{
Takotsubo Cardiomyopathy and Acute Ischemic Stroke
}

\author{
Alexandre Amaral-Silva ${ }^{\mathrm{a}, \mathrm{f}}$, Miguel Lourenco ${ }^{\mathrm{b}}$, Renato Fernandes ${ }^{\mathrm{c}}$, \\ Duarte Cacela $^{\mathrm{d}}$, Joao Alcantara ${ }^{\mathrm{e}}$
}

\begin{abstract}
Takotsubo cardiomyopathy and acute ischemic stroke. The Takotsubo cardiomyopathy is characterized by transient left ventricle dysfunction, with apical ballooning in the absence of significant coronary stenosis, and may clinically mimic an acute myocardial infarction. The association between Takotsubo cardiomyopathy and several acute neurological conditions has been increasingly described. The authors present the case report of an acute stroke patient submitted to intravenous thrombolysis, whose EKG on admittance showed supra-ST deviation in DI, AVL and V2-V6 leads, with concomitant elevation of myocardial necrosis biomarkers. After intravenous thrombolysis, a cardiac catheterism was performed that showed apical ballooning and acinesia of the left ventricle with decreased ventricular function, with no significant coronaropathy. The cerebral MRI performed on the seventh day showed multiple acute infarctions in different vascular territories of the anterior and posterior circulations bilaterally. Transthoracic echocardiogram performed on the same day revealed normal ventricular function and myocardial kinetics supporting the diagnosis of Takotsubo cardiomyopathy. The patient was discharged on day 10, on hypocoagulation therapy. Takotsubo cardiomyopathy is a spontaneously reversible condition, mostly requiring supportive therapeutic mea-
\end{abstract}

Manuscript accepted for publication July 10, 2012

${ }^{a}$ Unidade CerebroVascular do Hospital de Sao Jose, Centro Hospitalar de Lisboa Central, EPE, Lisboa, Portugal

${ }^{b}$ Neurology Department, Hospital de Santo Espirito de Angra do Heroismo ESPR, Angra do Heroismo, Portugal

${ }^{\mathrm{c}}$ Cardiology Department, Hospital do Espirito Santo, EPE, Evora, Portugal

${ }^{\mathrm{d}}$ Cardiology Department, Hospital de Santa Marta, Centro Hospitalar de Lisboa Central, EPE, Lisboa, Portugal

${ }^{\mathrm{e}}$ Unidade CerebroVascular do Hospital de Sao Jose, Centro Hospitalar de Lisboa Central, EPE, Lisboa, Portugal

${ }^{\mathrm{f}}$ Corresponding author: Alexandre Amaral-Silva,Unidade Cerebro Vascular, Hospital de S. Jose, Rua Antonio Jose Serrano, 1150-199

Lisboa, Portugal. Email: zefiros@netcabo.pt

doi: http://dx.doi.org/10.4021/jmc776w sures. The acute left ventricle dysfunction characteristic of this syndrome is a potential mechanism for cardiac embolism. Acute ischemic stroke is a relatively rare but severe complication. According to this, hypocoagulant therapy must be considered especially until the ventricular function is fully recovered.

Keywords: Takotsubo cardiomyopathy; Apical ballooning; Left ventricle dysfunction; Stroke; Hypocoagulation

\section{Introduction}

Described by Sato et al [1] in 1990, Takotsubo's cardiomyopathy is characterized by transient left ventricular dysfunction, with apical ballooning, apical hypocinesia/acinesia and basal hypercontractility, in the absence of significant coronary stenosis. It may clinically and electrocardiographically mimic an acute myocardial infarction [1,2]. Elevation of cardiac ischemia biomarkers, usually mild and transient, can also be a feature of this condition [3]. The differential diagnosis with acute coronary syndrome is established by coronary angiography. Exclusion of other cardiovascular conditions like myocarditis, pericarditis or aortic dissection is also important. Recently diagnostic guidelines for Takotsubo's cardiomyopathy have been published [4].

Takutsubo's cardiomyopathy is a transient condition and normalization of left ventricular function has been described between 7 to 37 days [3]. Electrocardiographic normalization usually takes longer-19 to 219 days [5]. The prevalence of this condition has been estimated to be 0.7 to $2.5 \%$ among patients with suspected acute coronary syndrome and elevated ST-segment $[3,5,6]$. Almost $90 \%$ of all reported cases have been described in postmenopausal women reporting previous history of extreme psychological/emotional stress $(80 \%)$ or in association with physical stress factors like severe trauma, surgery, severe hypoglycemia, asthma decompensation, etc. $(20 \%)[3,7]$. Association with several neurological conditions, like seizures [8] or Guillain Barre syndrome [9], has been increasingly reported.

The authors discuss the physiopathological and temporal relation between acute ischemic stroke and Takotsubo cardiomyopathy. 


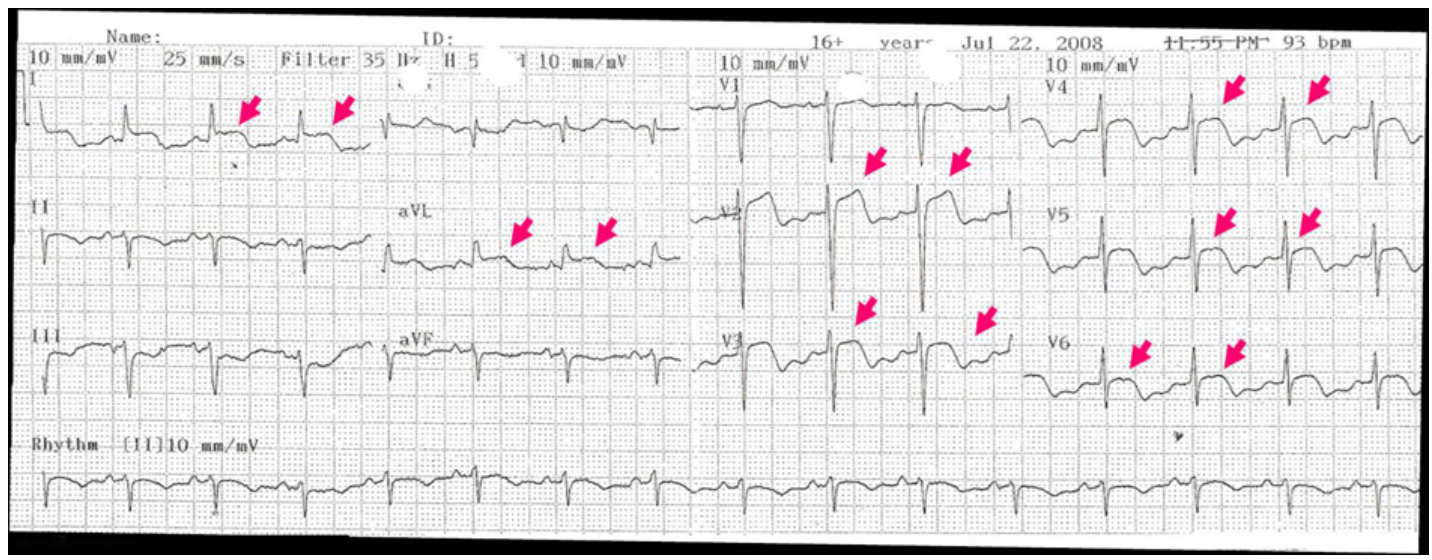

Figure 1. Electrocardiogram performed on admission showed supra ST deviation and inverted T waves in DI, AVL and V2-V6 leads (colored arrows)

\section{Case Report}

Seventy-year-old woman, with past medical history of depression, parkinsonism, arterial hypertension and dyslipidemia. No previous history of atrial fibrillation has been reported. She was on clopidogrel, indapamide, captopril, bisoprolol, transdermic nitroglycerine, levodopa/carbidopa and olanzapine. She was admitted because of right hemiparesis and motor aphasia (National Institute Health Stroke Scale Score $($ NIHSSS $)=6$ ), 50 minutes after symptoms-onset. There was no previous or concomitant history of physical or psychological stress. CT scan on admittance showed no acute ischemic or hemorrhagic lesions. The patient was treated with i.v. t-PA one hour and 30 minutes after symptom-onset. EKG on admittance showed sinus rhythm, ST elevation and negative, symmetric T waves in I, AVL and V2-
V6 (Fig. 1). Blood chemistry evidenced elevated myocardial necrosis biomarkers (CPK: 601U/L and troponine T: $0.9 \mathrm{ng} /$ $\mathrm{mL}$ ) and a Pro-BNP of $24855 \mathrm{pg} / \mathrm{mL}$.

Neurological deterioration was observed one hour after the thrombolytic therapy have been finished - NIHSSS $=15$. Another CT scan and EKG were immediately performed that were similar to the ones performed on admittance. It was decided to perform a cardiac angiography that documented apical ballooning and acinesia, basal hypercontractility and decreased left ventricular function, in the absence of coronary stenosis (Fig. 2).

The control CT performed on the 3rd day showed a left temporo-parieto-occipital acute ischemic lesion and a right parasagittal hemorrhagic infarction. The cerebral MRI performed on the 7th day documented a large acute ischemic lesion in the territory of the left middle cerebral artery (MCA)
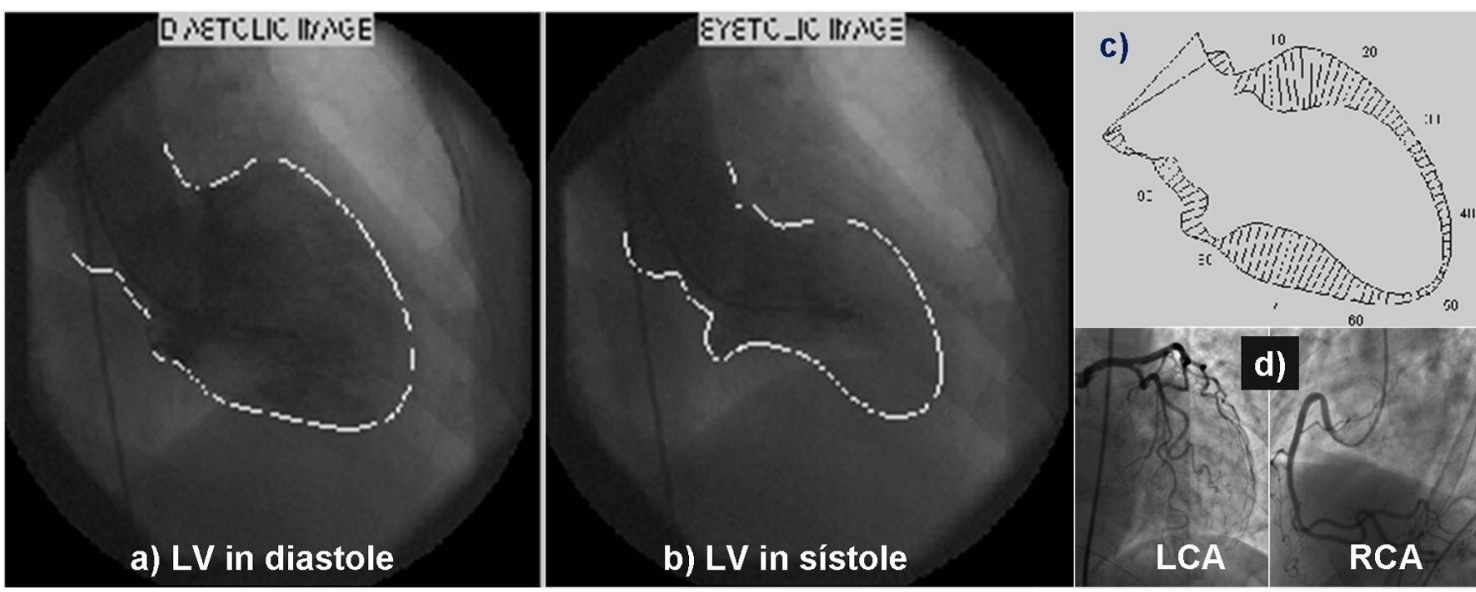

Figure 2. Ventriculography on diastole (a) and systole (b), showing apical ballooning and acinesia and left ventricle basal hypercontractility with compromised systolic function (c). Coronariography (d) showing no stenotic lesions in left and right coronary arteries. LV: Left ventricle, LC: left coronary artery, RC: right coronary artery. 


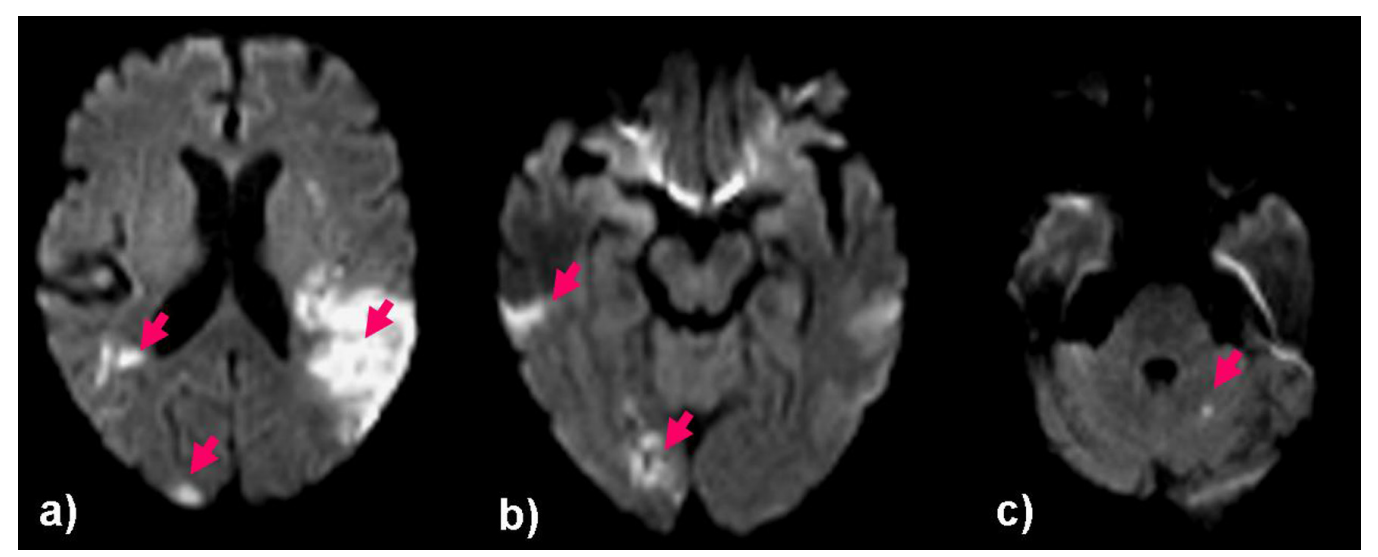

Figure 3. Cerebral MRI performed at the 7th day-DWI sequence-Showing multiple acute ischemic lesions: large left temporoparietal and insular ischemic infarct (a), multiple small infarcts in right medial and posterior cerebral arteries (a, b) and small left cerebellar hemispheric infarct (c).

and multiple small ischemic lesions in the left MCA and posterior cerebral artery (PCA) and ipsilateral cerebellar hemisphere (Fig. 3). In the same day blood chemistry showed normal cardiac biomarkers. The transesophageal echocardiogram showed no embolic sources and documented left ventricular function and myocardial kinetics normalization, supporting the diagnosis of left ventricle's transient dysfunction. The remaining tests performed (namely carotid triplex scan and transcranial color coded duplex) were normal. Considering the probable cardioembolic etiology of stroke, and despite normalization of left ventricle's function, it was decided to start hypocoagulation with warfarin. Regarding complications during admission, transitory hypotension requiring no specific therapeutical measures, during the first five days, has to be mentioned.

Patient was discharged home on the 10th day, functionally dependent (Modified Rankin scale score $=4$ ). No complications, cardiac or neurologic were observed during the one-year period of follow up. It was decided to stop hypocoagulation after echocardiography reevaluation performed 9 months after discharge, that showed normal left ventricle function and no embolic sources.

\section{Discussion}

The morphological features documented in the ventriculography, without evidence of coronariopathy, strongly suggest the diagnosis of Takotsubo's cardiomyopathy. Although early administration of t-PA could be responsible for dissolving some thrombi or emboli, precluding their identification in the coronariography, complete normalization of left ventricle function in a patient with anterior wall myocardial infarction would be unlikely. Furthermore, the contractility changes documented in the ventriculography involved different coronary vascular territories making it improbable.
Only multiple vessel embolization could explain this situation and this is also not likely to happen in coronary vessels.

Takotsubo's cardiomyopathy is a spontaneously reversible condition that most often requires only general support measures. More than $95 \%$ of the patients recover completely and recurrence is rare [3, 10]. Cardiogenic shock, acute pulmonary edema, pulmonary thromboembolism, cardiac (atrial and ventricular) arrythmias and stroke are the most severe acute complications [10] and the mortality rate associated with this condition is calculated between 1 and $10 \%$. The pathogenic mechanisms are not completely understood. Proposed mechanisms include diffuse coronary vasospasm $[1,2]$, changes in coronary microvascular function [11], catecholamine mediated cardiotoxicity [12], or myocarditis [7].

Acute left ventricular dysfunction is a potential mechanism of cardiac embolism. Thrombi formation in left ventricular apex is calculated to happen in about $2.5 \%$ of these patients, justifying a $0.8 \%$ incidence rate of thromboembolic complications [13].

Although, in this particular case report, there was no reference to a preceding physical or emotional stress situation, the past medical history of humor disturbance requiring chronic antidepressants treatment may represent a contributing factor to the cardiomyopathy's development. This hypothesis is strongly supported by documentation of electrocardiographic and cardiac biomarker changes immediately after hospital admission (about two hours after symptoms onset). In fact, it is well known that troponine $\mathrm{T}$ levels take about three to four hours to become pathologically increased even in patients with transmural myocardial infarction, therefore corroborating the proposed sequence of events. Data published in a literature review by Yoshimura et al [14] in 2008 support this hypothesis. In fact, in most of the reported patients, with stroke preceding the cardiomyopathy documentation, the clinical, laboratorial and especially electrocardiographic manifestations appeared mostly between 
two and a half hours and twelve days after stroke diagnosis.

The imagiological documentation of ischemic lesions in multiple vascular territories, suggesting and embolic mechanism, is another argument favoring the etiological relation between left ventricular dysfunction and stroke, even if no visible left ventricular thrombi was identified and, especially, in the absence of atrial fibrillation or other embolic sources.

Stroke associated with Takotsubo's cardiomyopathy is usually severe [14]. As well as in our case report, more than $30 \%$ of all strokes reported in the literature, as a cause or consequence of Takotsubo's cardiomyopathy, were associated with major neurological deficits (NIHSSS equal or superior to 15). This is true either for anterior or posterior circulation strokes [14]. Another finding reported in the literature, and observed in our patient, is the common presence of ischemic lesions in the insular area in patients with Takotsubo's cardiomyopathy. This fact has been hypothesized to be of etiological relevance, with insular lesions probably contributing to the development of the cardiomyopathy and justifying the association between both entities [14].

Another finding to be highlighted in our case report is the significant increase in cardiac biomarkers (namely pro$\mathrm{BNP}$ ), especially when compared to the usual values reported in the literature [14]. This is particularly relevant once it is presently discussed the relation between the magnitude of this increase and the severity of the ventricular dysfunction [7].

Regarding the therapeutical approach, and considering the potential risk of embolic events, many authors advocate the use of hypocoagulants, at least until complete normalization of the left ventricular function. The use of these pharmacological agents is mandatory in case of intraventricular thrombus documentation $[7,15]$. In our patient, it was decided not to initiate hypocoagulation immediately considering the extension of the ischemic brain lesions and the risk of hemorrhagic transformation. Treatment was started by the end of the first week. Considering the potential risk of recurrence and the fact that the patient was bedridden it was decided to maintain warfarin despite complete recovery of the left ventricular function and the absence of intra-cardiac thrombus. This treatment was stopped nine month after discharge after echocardiographic reevaluation and mild functional improvement.

\section{Conflict of Interests}

The authors declare no conflict of interests related to this manuscript.

\section{References}

1. Satoh H, Tateishi H, Uchida T, Dote K, Ishihara M. Ta- kotsubo-type cardiomyopathy due to multivessel spasm. In: Kodama K, Haze K, Hon M, editors. Clinical Aspect of Myocardial Injury: From Ischemia to Heart Failure. Tokyo: Kagakuhyouronsya Co.,1990: 56-64.

2. Dote K, Sato H, Tateishi H, Uchida T, Ishihara M. [Myocardial stunning due to simultaneous multivessel coronary spasms: a review of 5 cases]. J Cardiol. 1991;21(2):203-214.

3. Pilgrim TM, Wyss TR. Takotsubo cardiomyopathy or transient left ventricular apical ballooning syndrome: A systematic review. Int J Cardiol. 2008;124(3):283-292.

4. Kawai S, Kitabatake A, Tomoike H. Guidelines for diagnosis of takotsubo (ampulla) cardiomyopathy. Circ J. 2007;71(6):990-992.

5. Matsuoka K, Okubo S, Fujii E, Uchida F, Kasai A, Aoki T, Makino K, et al. Evaluation of the arrhythmogenecity of stress-induced "Takotsubo cardiomyopathy" from the time course of the 12-lead surface electrocardiogram. Am J Cardiol. 2003;92(2):230-233.

6. Abdulla I, Kay S, Mussap C, Nelson GI, Rasmussen HH, Hansen PS, Ward MR. Apical sparing in tako-tsubo cardiomyopathy. Intern Med J. 2006;36(7):414-418.

7. Prasad A, Lerman A, Rihal CS. Apical ballooning syndrome (Tako-Tsubo or stress cardiomyopathy): a mimic of acute myocardial infarction. Am Heart J. 2008;155(3):408-417.

8. Lemke DM, Hussain SI, Wolfe TJ, Torbey MA, Lynch JR, Carlin A, Fitzsimmons BF, et al. Takotsubo cardiomyopathy associated with seizures. Neurocrit Care. 2008;9(1):112-117.

9. Bernstein R, Mayer SA, Magnano A. Neurogenic stunned myocardium in Guillain-Barre syndrome. Neurology. 2000;54(3):759-762.

10. Gianni M, Dentali F, Grandi AM, Sumner G, Hiralal R, Lonn E. Apical ballooning syndrome or takotsubo cardiomyopathy: a systematic review. Eur Heart J. 2006;27(13):1523-1529.

11. Kurisu S, Inoue I, Kawagoe T, Ishihara M, Shimatani Y, Nakamura S, Yoshida M, et al. Time course of electrocardiographic changes in patients with tako-tsubo syndrome: comparison with acute myocardial infarction with minimal enzymatic release. Circ J. 2004;68(1):7781.

12. Wittstein IS, Thiemann DR, Lima JA, Baughman KL, Schulman SP, Gerstenblith G, Wu KC, et al. Neurohumoral features of myocardial stunning due to sudden emotional stress. N Engl J Med. 2005;352(6):539-548.

13. de Gregorio C, Grimaldi P, Lentini C. Left ventricular thrombus formation and cardioembolic complications in patients with Takotsubo-like syndrome: a systematic review. Int J Cardiol. 2008;131(1):18-24.

14. Yoshimura S, Toyoda K, Ohara T, Nagasawa H, Ohtani $\mathrm{N}$, Kuwashiro T, Naritomi H, et al. Takotsubo cardiomyopathy in acute ischemic stroke. Ann Neurol. 
2008;64(5):547-554.

15. Ramirez-Moreno JM, Bejarano-Moguer V, Elduayen J, Millan-Nunez MV, Pons-Garcia MA, Gomez MJ, No-
gales-Asensio JM. [Ischemic stroke due to transient left ventricular apical ballooning in women with epilepsy debut]. Rev Neurol. 2009;48(6):333-335. 